Int. J. Dev. Biol. 48: 743-753 (2004)

doi: $10.1387 / \mathrm{ijdb} .041877 \mathrm{ad}$

\title{
Conservation and non-conservation of genetic pathways in eye specification
}

\author{
AMY L. DONNER and RICHARD L. MAAS* \\ Division of Genetics, Department of Medicine, BWH and HMS, Boston, MA, USA
}

\begin{abstract}
In this review we highlight two genetic pathways important for eye morphogenesis that are partially conserved between flies and vertebrates. Initially we focus on the eyparadigm and establish which aspects of this genetic hierarchy are conserved in vertebrates. We discuss experiments that evaluate the non-linear relationship amongst the genes of the hierarchy with a concentration on vertebrate functional genetics. We specifically consider the Six genes and their relationship to sine oculis, as tremendous amounts of new data have emerged on this topic. Finally, we highlight similarities between Shh/Hh directed morphogenesis mediated by basic Helix-LoopHelix factors in vertebrate retinal cell specification and in specification of fly photoreceptors.
\end{abstract}

KEY WORDS: bHLH gene, eyeless, lens, neural retina, Pax6

\section{Introduction}

Developmental and evolutionary biologists have identified numerous protein families that maintain high sequence conservation across metazoan phyla. Analysis of these gene families reveals a striking conservation of both gene function and of the relationships among gene families in the patterning of analogous structures in evolutionarily distant organisms. In this review we will focus on the genetic hierarchies that control morphogenesis of the vertebrate eye, and we will compare them to the genetic pathways that control patterning of the compound eye of the fruit fly, Drosophila. In particular, we will review the Drosophila eyeless paradigm that is involved in patterning the fly eye disc and we will assess the conservation of this pathway in the vertebrate lens and retina. Finally, we will review the hedgehog $(h h)$ dependent regulation of bHLH transcription factors that specify the Drosophila R8 photoreceptor and we will discuss the similarity to the specification of retinal cell fate by Sonic hedgehog (Shh) and bHLH transcription factors.

\section{Definition of the eye fields}

\section{The fly eye field}

In Drosophila, the eye-antennal disc invaginates from the embryonic ectoderm and for most of three larval stages these epithelial cells proliferate without differentiating. At the end of the third instar larval period, however, a transition from a monolayer of ectoderm to a highly organized compound eye begins with the formation of the morphogenetic furrow (MF) at the posterior edge of the eye imaginal disc (see Fig. 1). Subsequently, a wave of differentiation sweeps across the disc as the MF moves from posterior to anterior. In the anterior compartment the cells are unpatterned and proliferate asynchronously. Just prior to entering the MF, cells become synchronized in the G1 phase of the cell cycle. In the wake of the MF, differentiation of photoreceptor cells begins with the specification of R8, which is necessary for all subsequent cells to be specified and recruited. $R 8$ quickly recruits $\mathrm{R} 2, \mathrm{R} 3, \mathrm{R} 4$, and $\mathrm{R} 5$ to form a pre-cluster. The remaining unspecified cells undergo a second mitotic division prior to specification of the final 14 precursor cells, including four cells that secrete the lens and crystalline cone and six pigment cells that optically isolate each ommatidium. The $19^{\text {th }}$ founder cell divides twice to form the 4-cell mechanosensory bristle (reviewed in Baker, 2001; Hsiung and Moses, 2002). Thus, the transformation of the fly eye imaginal disc from a sheet of proliferative epithelial cells to a highly organized array of approximately 800 ommatidia provides a powerful and genetically tractable system to understand the genetic hierarchies that control patterning and morphogenesis.

Abbreviations used in this paper: AEL, anterior epithelial layer; Ato, atonal; bHLH, basic helix-loop-helix transcriptional regulator; dac, dachshund; Dpp, decapentaplegic; E, embryonic day; ey, eyeless; eyg, eyegone; eya eyes absent; GCL, ganglion cell layer; Hh, hedgehog; INL, inner nuclear layer; LP, lens placode; MF, morphogenetic furrow; NR, neural retina; OC, optic cup; ON, optic nerve; ONL, outer nuclear layer; OS, optic stalk; OV, optic vesicle; P, postnatal day; PN, proneural; PPN, pre-proneural; RGC, retinal ganglion cell; RPE, retinal pigmented epithelium; Shh, Sonic hedgehog; so, sine oculis; toy, twin of eyeless.

\footnotetext{
*Address correspondence to: Dr. Richard L. Maas. Harvard Medical School-NRB 458H, 77 Louis Pasteur Avenue, Boston, MA 02115, USA. Fax: +1-617-525-4751. e-mail: maas@receptor.med.harvard.edu
} 


\section{The vertebrate eye field}

In vertebrates, the eye field develops mainly from two separate but interactive tissues, the anterior neurectoderm and the head surface ectoderm. The retinal anlage is specified at the end of gastrulation in the anterior neurectoderm. This eye field splits into two symmetric retinal primordia that evaginate from the forebrain as optic vesicles (OV; Fig. 2). Each OV closely approaches the overlying surface ectoderm of the head. The close apposition between the vesicle and the head ectoderm results in the induction of the lens placode (LP), a thickened layer of ectoderm composed of a pseudo-stratified columnar epithelium. The LP and the OV remain closely apposed as development proceeds. Invagination of the OV results in a bi-layered structure that is patterned along a proximal-distal axis into optic stalk (OS), retinal pigmented epithelium (RPE), and neural retina (NR). Invagination of the LP results in the formation of the lens vesicle, which pinches off from the surface ectoderm. Cells in the posterior half of the lens vesicle elongate through the vesicle and differentiate into primary fiber cells. The anterior epithelial layer $(A E L)$ in the lens remains proliferative and cells produced in the AEL migrate laterally to the equatorial region of the lens where they differentiate into secondary fiber cells (reviewed in Ogino and Yasuda, 2000; AsheryPadan and Gruss, 2001).

Differentiation in the mouse NR begins at the OS, extends to the central retina, and spreads as a wave to the peripheral retina (McCabe et al., 1999). Retinal cell fate determination in the mouse occurs over a broad period of time (E12 to P21) and involves the cessation of mitosis (birth), commitment to one of seven major cell fates, migration from the ventricular portion of the retina to the appropriate cell layer in the laminate retina, and differentiation (Cepko et al., 1996). The first neurons born in the vertebrate eye are always retinal ganglion cells (RGCs), while the birth order of the other retinal cell types varies among species (Cepko et al., 1996). In mice, the birth order for mature retinal cells begins with RGCs and cone photoreceptors, followed by amacrine and horizontal cells, and lastly, rod photoreceptors, bipolar cells, and Müller glia are specified. There is tremendous overlap in the timing of speci-

TABLE I

DROSOPHILA EYE SPECIFICATION GENES AND THEIR VERTEBRATE COUNTERPARTS

\begin{tabular}{|c|c|c|c|}
\hline Drosophila & Vertebrate & Eye Phenotype (loss of function) & References \\
\hline Ey & Pax6 & small eyes, anophthalmia, Aniridia & $\begin{array}{l}\text { Hill et al., 1991; } \\
\text { Glaser et al., } 1994\end{array}$ \\
\hline Eya & Eya1-3 & $\begin{array}{l}\text { Eya1:open eyelids } \\
\text { EYA1: anterior segment anomalies }\end{array}$ & $\begin{array}{l}\text { Xu et al., 1997; } \\
\text { Azuma et al., } 2000\end{array}$ \\
\hline So & $\operatorname{Six} 1 / 2$ & none & Laclef et al., 2003 \\
\hline Optix & $\operatorname{Six} 3 / 6$ & holoprosencephaly, anophthalmia & $\begin{array}{l}\text { Gallardo et al., 1999; } \\
\text { Wallis et al., 1999; } \\
\text { Pasquier et al., 2000; } \\
\text { Li et al., 2002; }\end{array}$ \\
\hline$D$-six4 & Six $4 / 5$ & Six5: adult onset cataracts & $\begin{array}{l}\text { Sarkar et al., 2000; } \\
\text { Klesert et al., 2000; } \\
\text { Winchester et al., } 1999\end{array}$ \\
\hline Dac & Dach1 & none & Davis et al., 2001 \\
\hline$H h$ & Shh & holoprosencephaly, cyclopia & Chiang et al., 1996 \\
\hline Atonal & $\begin{array}{l}\text { Math5 } \\
\text { (Xath5, ath5) }\end{array}$ & $>80 \%$ loss of RGCs & $\begin{array}{l}\text { Brown et al., 2001; } \\
\text { Wang et al., } 2001\end{array}$ \\
\hline hairy & Hes1 & $\begin{array}{l}\text { premature retinal neurogenesis } \\
\text { resulting in a retina with very few } \\
\text { of each major type of neuron }\end{array}$ & Tomita et al., 1996 \\
\hline
\end{tabular}

fication owing to the acquisition of properties such as competence and bias which are not tightly defined temporally (reviewed in Cepko et al., 1996; Marquardt and Gruss, 2002). In this review, we will focus on genetic aspects of the Drosophila eye morphogenetic process that are conserved, at least in part, in vertebrate lens and retinal development.

\section{The eyeless paradigm in Drosophila}

Studies on the paired domain containing transcription factor encoded by the eyeless (ey) gene have been central to our understanding of eye morphogenesis in Drosophila. Eywas coined the "master regulator" of Drosophila eye development since removal of eyfrom the eye disc abolishes eye formation (Quiring et al., 1994), and ectopic eyexpression initiates ectopic eye formation (Halder et al., 1995). We now know that eyis one of several genes (ey, twin of eyeless (toy); sine oculis (so); eyes absent (eya); and dachshund (dac); see Fig. 1 and Table I) that form a nonlinear network of regulatory interactions essential for fly eye morphogenesis. This pathway has been reviewed extensively elsewhere (Desplan, 1997; Gehring and Ikeo, 1999; Wawersik and Maas, 2000). For the purposes of this review, we will refer to this genetic network as the ey paradigm.

\section{Conservation and non-conservation of the eyeless paradigm}

Since the elucidation of the eyparadigm in the Drosophila eye and the identification of highly related genes in vertebrates, the extent to which the paradigm has been conserved during vertebrate eye morphogenesis has been of considerable interest (Table I). However, comparison of the corresponding genetic networks between Drosophila and vertebrates has been complicated by the existence of multiple members of the respective gene families. Ey was originally placed at the top of the genetic hierarchy required for Drosophila eye specification. Subsequently, two Drosophila eyrelated genes have been found, twin of eyeless (toy) and eyegone (eyg), see Czerny et al., 1999 and Jang et al., 2003. Both of these genes are required for eye formation and function in unique capacities. Toy acts upstream of $e y$, directly inducing eyexpression in the eye disc (Hauck et al., 1999; Czerny et al., 1999), and is dependent upon ey for its function (Czerny et al., 1999). Toyis not regulated by ey, eya, so, or dac(Czerny et al., 1999). Eyg, on the other hand, acts in a pathway independent of ey (Jang et al., 2003), and plays an entirely separate role during eye development (Dominguez et al., 2004). Eygpromotes growth of the eye disc and acts downstream of Notch (Dominguez et al., 2004).

In Drosophila, two additional so family members, optix and $D$ six4, have also been found (Kawakami et al., 2000; Table I). Like eyg, optixis essential for eye development but is not involved in the same signaling network as so (Seimiya and Gehring, 2000). D six4, on the other hand, is not expressed in the fly eye (Kawakami et al., 2000). In vertebrates, the gene families are for the most part larger, and it is therefore difficult to define orthologues. There exists one ey/toy/eyg homologue (Pax6), six soloptix/D-six4 homologues (Six1-6) (Kawakami et al., 2000), four eya homologues (Eya1-4) (Xu et al., 1997; Borsani et al., 1999), and two dac homologues (Dach1and Dach2) (Hammond etal., 1998; Caubit et al., 1999; Davis et al., 1999; Heanue et al., 1999). 


\section{Defining vertebrate orthologues}

Pax6 is more closely related to toyand eythan to eyg (Gehring and Ikeo, 1999), and may have taken on the functional role of both eyand toyin vertebrate eye specification (Plaza et al., 1993). Eyg, on the other hand, shares both sequence and functional homology and with the Pax6 isoform Pax6(5a) (Dominguez et al., 2004). The central role that Pax6 plays in vertebrate eye formation and its remarkable similarity to ey has been reviewed extensively (Gehring and Ikeo, 1999; Wawersik and Maas, 2000; AsheryPadan and Gruss, 2001; Hansen, 2001; van Heyningen and Williamson, 2002; Simpson and Price, 2002), and will be only briefly reviewed here.

The Six genes fall into three gene families: Six 1/Six2/so, Six3/ Six6/optix, and Six4/Six5/D-six4. This classification is based upon molecular phylogeny, chromosomal arrangement, DNA binding specificity, and the ability to interact with Eya proteins (Kawakami et al., 2000). Surprisingly, one of the so orthologues, Six 1 , is not expressed during vertebrate eye morphogenesis, and homozygous deletion of Six 1 has no affect on eye development (Oliver et al., 1995; Laclef et al., 2003). Six2 is expressed in the inner and outer nuclear layers (INL and ONL) and the ganglion cell layer (GCL) of the adult mouse retina (Kawakami et al., 1996), but ectopic expression of Six2 in developing medaka fish has no affect on eye morphogenesis (Loosli et al., 1999). Thus, it is unlikely that Six 1or Six 2 is an essential part of a signaling network in vertebrate eye morphogenesis.

Both optix orthologues, Six3and Six6, are expressed throughout eye morphogenesis (Jean et al., 1999), and homozygous mutation of Six6 in mice deletes the optic chiasm and $O N$ and causes retinal hypoplasia ( $\mathrm{Li}$ et al., 2002). Deletion of Six3 expression in medaka fish with a morpholino completely deletes all eye and forebrain structures (Carl et al., 2002). These results indicate that Six 3 and Six 6 are required for vertebrate eye formation, and we will therefore discuss the likelihood that one or both of these genes plays a role comparable to that of so in the Drosophila ey paradigm.

The remaining two vertebrate Six genes, Six4 and Six5, are orthologous to $D$-six 4 , which is not expressed in the fly eye (Kawakami et al., 2000). Six 4 is expressed in the lens placode of Xenopus embryos (Ghanbari et al., 2001). Six4, however, is not expressed in the developing eyes of mouse embryos, and homozygous deletion of Six 4 has no effect on eye morphology (Ozaki et al., 2001). Six4 is also not expressed in the developing eyes of zebrafish embryos (Kobayashi et al., 2000). Thus, like Six 1 and Six2, Six4does not play a major role in the specification of the vertebrate eye. Although Six5 is only weakly expressed in the developing mouse lens (Heath etal., 1997; Sarkar etal., 2000) and in the adult NR (Kawakami et al., 1996), mice with either heterozygous or homozygous deletion of Six5develop cataracts (Sarkar et al., 2000; Klesert et al., 2000). Similarly, disruption of the DMPK/SIXS locus in humans causes myotonic dystrophy, with symptoms including adult onset cataracts (Winchester et al., 1999). Since both mice and humans deficient in Six5 develop cataracts postnatally, Six 5 likely plays a role in the maintenance of adult lenses. Since there is less evidence supporting a critical role for Six 5 during embryonic eye specification we will focus on Six3and Six6in our consideration of a vertebrate equivalent of $s o$.

Eya1, Eya2, and Eya3are also expressed during eye development (Xu, et al., 1997; Purcell, 2002), while Eya4 is expressed in the embryonic craniofacial region, but not in the developing eye (Borsani et al., 1999). Thus, we will focus on the comparison of eya to Eya1, 2, and 3, the vertebrate Eya genes that are expressed during vertebrate eye development. Lastly, Dach1 is expressed in the retina in a pattern overlapping with, albeit delayed from, Pax6 (Hammond et al., 1998; Caubit et al., 1999; Heanue et al., 2002). Dach2, on the other hand, is not expressed in the eye (Heanue et al., 1999), and thus, we will compare and contrast dac with Dach1.

\section{The activity of Pax6 and eyeless is conserved}

Similar to ey (Quiring et al., 1994), Pax6expression is found in the eye as soon as the eye field can be identified. This is true, both in the retinal anlage specified in the anterior neurectoderm and in the presumptive head ectoderm that becomes the lens placode (Walther and Gruss, 1991). As seen with eymutations in the fly, disruption of Pax 6 severely affects vertebrate eye formation.

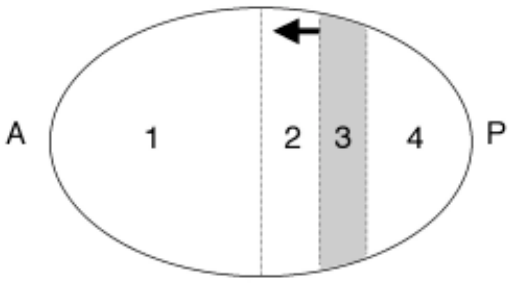

Drosophila Eye Disc

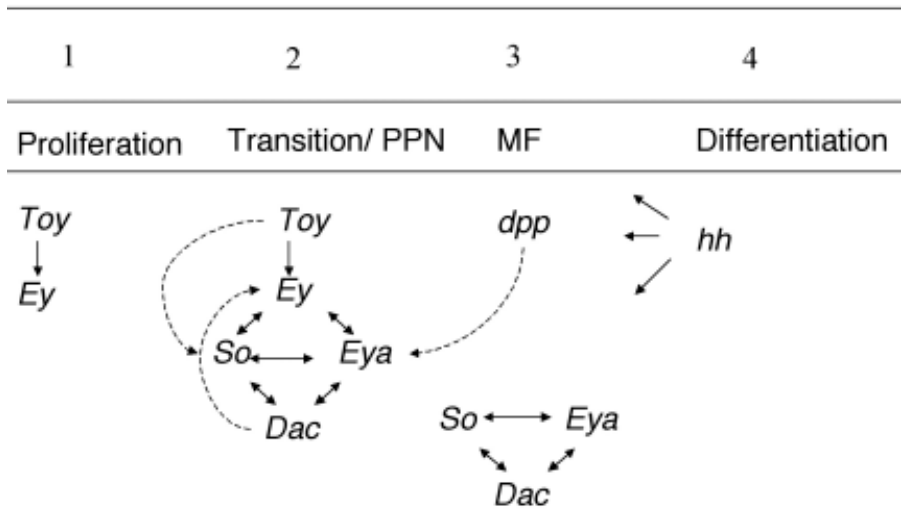

Fig. 1. Schematic representation of Drosophila eye development. Differentiation of the Drosophila eye is controlled by a complex series of signaling events that produce precise compartmentalization of transcription factor activity. The MF, marked by hatched lines, is a wave of differentiation that moves from posterior $(P)$ towards anterior $(A)$ across the eye field during the third instar larvae. Compartments of the eye disc are divided by a dotted line. Compartment 1 represents the majority of cells anterior to the MF. The pre-proneural (PPN) region, represented by compartment 2, is just anterior to the MF. Compartment 3 represents the MF. The arrow indicates the direction of furrow progression. In the compartment 4, posterior to the MF, photoreceptor differentiation and ommatidia assembly occur. Below both the major cellular events and the expression domains of ey paradigm genes are indicated. Ey and toy are only expressed anterior to the MF. In the PPN region, ey and toy induce expression of so, while ey and dpp induce expression of eya. Together ey, so, and eya activate dac. The nonlinear regulatory relationship amongst these genes is illustrated and is herein referred to as the eyeless paradigm. Just posterior to the MF furrowso, eya, and dac continue to be expressed in the absence of eye. 

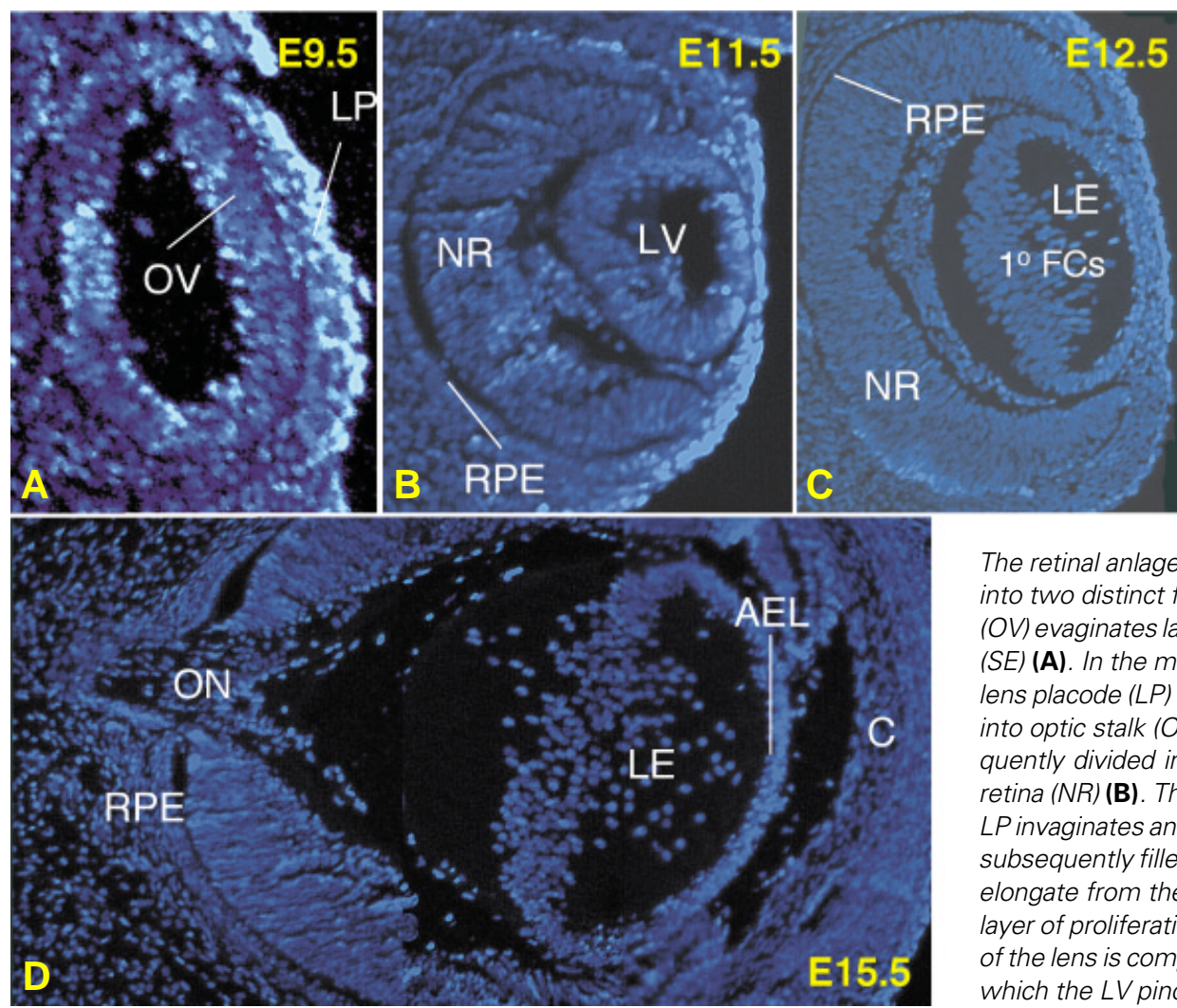
The retinal anlage, specified in the anterior neurectoderm, is divided into two distinct fields (not shown). From each field an optic vesicle (OV) evaginates laterally and opposes the overlying surface ectoderm (SE) (A). In the mouse, the surface ectoderm is induced to form the lens placode (LP) at roughly E9. The OV is patterned proximal-distally into optic stalk (OS) and optic cup (OC, not shown), which is subsequently divided into retinal pigmented epithelium (RPE) and neural retina (NR) (B). The OS matures to form the optic nerve (ON, D). The $L P$ invaginates and forms a hollow lens vesicle ( $L V$; panel $B)$, which is subsequently filled with differentiating primary fiber cells (10 FC) that elongate from the posterior (C). In the mature lens (LE), an anterior layer of proliferative epithelial cells (APE) remains and the remainder of the lens is composed of fiber cells (D). The surface ectoderm from which the $L V$ pinches off from gives rise to the cornea (C in D).
Homozygous or compound heterozygous mutation of the Pax6 gene results in anophthalmia in both humans (Glaser et al., 1994) and PaxG Sey mice (Hill et al., 1991).

Similarly, in the zebrafish mutant cyclops, which lacks Shh expression, the Pax6expression domain is expanded and retina specification occurs at the expense of the optic nerve (Macdonald et al., 1995). Ectopic expression of Shh, on the other hand, restricts Pax6 expression, and nearly abolishes the retinal field (Macdonald et al., 1995). Thus, alterations in Shh alter Pax6 expression. This is reminiscent of the fly, where down-regulation of eyin the MF coincides with cells receiving Hh signals (Halder et al., 1998).

Ectopic Pax6 expression in Xenopus embryos can produce various eye related phenotypes including the induction of wellorganized, ectopic eyes in the head anterior to the hindbrainspinal cord junction (Chow et al., 1999). This observation is reminiscent of the ectopic eye forming activity of eyin Drosophila imaginal discs (Halder et al., 1995). Collectively, these experiments show that specification of the eye in vertebrates is tightly linked to Pax6expression. Clearly, Pax6in the vertebrate eye has retained some striking functional similarities with ey.

\section{Do non-orthologous genes in the vertebrate eye fulfill the role of so?}

The ey paradigm is used during vertebrate organogenesis in tissues unrelated to the eye. In two such examples, a gene family member has been substituted into the hierarchy. In the developing kidney, homozygous deletion of Eya1, Pax2, or Six1disrupts early kidney morphogenesis (Torres et al., 1996; Xu et al., 1999; Xu et al., 2003). In addition, compound heterozygous mutants of Eya1 and Six 1 have hypoplastic kidneys (Xu et al., 2003, Li et al., 2003) demonstrating an interaction between these genes. While all of the ey paradigm interactions from the Drosophila eye are not conserved in the vertebrate kidney, enough parallels exist to establish the importance of the Pax2/Eya1/Six 1 genetic hierarchy for organogenesis (Torres et al., 1996; Xu et al., 1999; Xu et al., 2003). Pax2, however, is substituted for Pax6. In the developing somites, Pax3, Six1, Eya2, and Dach2 synergize to promote myogenesis (Heanue et al., 1999). In this example, Pax6 is replaced by the

TABLE II

QUALITATIVE AND FUNCTIONAL COMPARISON OF SIX3 AND SIX6 TO SO AND OPTIX

\begin{tabular}{|c|c|c|c|}
\hline Characteristic & Context & So & Optix \\
\hline Pattern of Expression & $\mathrm{N} / \mathrm{A}$ & - & + \\
\hline Eye Inducing Capacity & $\mathrm{N} / \mathrm{A}$ & - & + \\
\hline Null Mutations & $\mathrm{N} / \mathrm{A}$ & $\mathrm{NI}$ & $\mathrm{NI}$ \\
\hline Interaction with Eya proteins & $\mathrm{N} / \mathrm{A}$ & - & + \\
\hline \multicolumn{4}{|l|}{ Relationship with Pax6/Ey } \\
\hline & Mouse Lens (Six3) & + & - \\
\hline & Mouse NR & - & + \\
\hline & Fish NR & + & + \\
\hline & Frog NR (Six3) & + & - \\
\hline & Mouse OS (Six6) & - & + \\
\hline & Frog OS (Six3) & + & - \\
\hline & Fish RA (Six3) & + & + \\
\hline & Frog RA & + & - \\
\hline
\end{tabular}

In the vertebrate eye it is unclear if Six 3 and Six 6 function more like optix or like so. We assessed their role in vertebrate eye formation and have classified them as behaving either like optixor so. In some instances Six3and Six6have characteristics of both Drosophila genes. These instances are indicated by a (+) for each so and optix. Abbreviations; N/A, not applicable; NI, not informative; $(+)$ similar; (-) not similar; NR, neural retina; OS, optic stalk; RA, retinal anlage 
Pax3gene. Thus, there are clear examples in which the Drosophila eyparadigm has been utilized in vertebrate organogenesis, but the hierarchy has been modified by substituting tissue-appropriate family members.

Is it possible that a non-orthologous Six gene, Six3 or Six6, replaces the function of soin the vertebrate eye? As noted earlier, two Six genes are broadly expressed in the vertebrate eye during morphogenesis, Six3 and Six6 (Jean et al., 1999). These genes, however are orthologous to optix (Kawakami et al., 2000), which is expressed during and is important for eye development in Drosophila (Seimiya and Gehring, 2000), and not to so. To determine if Six 3 or Six 6 might replace so in the lens or NR, we would like to know whether these Six genes behave more like so or more like optix during vertebrate eye development. For both genes we will assess their qualitative and functional similarity to so and to optix by considering their temporal and spatial expression patterns, their ability to induce ectopic eyes, their homozygous null phenotypes, their regulatory relationships with PaxG, and their ability to interact with Eya proteins (Table II).

\section{Patterns of expression}

Optixand sohave different patterns of expression in Drosophila eye development (Seimiya and Gehring, 2000). Optix has an expression pattern similar to eyin the eye primordium and anterior to the MF in the differentiating disc, while so has an expression pattern comparable to eya, and is found in cells adjacent to and including the MF (Seimiya and Gehring, 2000). Six3 has an expression pattern nearly identical to that of Pax6, as both genes are found in the retinal anlage, the LP, and throughout the developing lens vesicle and OC (Walther and Gruss, 1991; Oliver et al., 1995). Six6 expression overlaps that of Pax6 in derivatives of the retinal anlage (optic stalk and neural retina) but is absent from the actual anlage (Toy et al., 1998; Toy and Sundin, 1999; Jean et al., 1999; Bernier et al., 2000). Six6is completely absent from the head surface ectoderm and its derivatives (Oliver et al., 1995; Toy et al., 1998; Toy and Sundin, 1999; Jean et al., 1999). Six3and Six6are expressed earlier than and more broadly than Eya1, Eya2or Eya3 (Xu et al., 1997). Thus, Six 3 and Six6 are expressed in patterns similar to that of Pax6, and therefore in this regard more closely resemble optix than so.

\section{Ectopic eye inducing capacity}

In the fly, ectopic expression of optix alone in the antennal disc induces eyes, whereas ectopic so expression does not (Seimiya and Gehring, 2000; Pignoni et al., 1997). Similar to optix, ectopic expression of Six3 in medaka fish induces ectopic retinal primordia in competent locations within the brain, and at a much lower frequency ectopic lenses in the head ectoderm near the otic vesicle (Loosli et al., 1999). In Xenopus ectopic expression of either Six3 or Six6 converts anterior neural plate to retina (Bernier et al., 2000.) In these experiments low concentrations of Six 3 of Six 6 expand the size of the retina, while high concentrations of either gene transform the midbrain to retina and delete the normal eye (Bernier et al., 2000). Thus, Six3and Six6resemble optixin their ability to induce an eyespecific developmental program in non-ocular tissue.

\section{Homozygous null phenotypes}

$S o$ is required for all aspects of visual system development in Drosophila (Cheyette et al., 1994; Serikaku and O'Tousa et al.,
1994), while an optix fly mutant has not been described. Six6null mice exhibit retinal hypoplasia and often lack both an optic nerve and an optic chiasm (Li et al., 2002). In addition, heterozygous mutation of $S / X 6$ in humans correlates with anophthalmia (Gallardo etal., 1999). Mutation of $S / X 3$ in humans causes holoprosencephaly, with phenotypes ranging from cyclopia to hypotelorism (Wallis et al., 1999; Pasquier et al., 2000). Morpholino inhibition of Six3 expression in medaka fish deletes both forebrain and eye tissue (Carl et al., 2002). The absence of an optix fly mutant makes it unclear whether Six 3 and Six6 mutation in vertebrates are more reminiscent of soor optix, although given the severity of each of the reported null phenotypes it is unlikely that this feature would provide a definitive distinction.

\section{Regulatory relationship to ey/Pax6}

In the fly, optix expression is truly independent of $e y$, as eyes ectopically induced by optix do not express ey, and optix can induce eyes in ey deficient flies (Seimiya and Gehring, 2000). In contrast, soexpression is dependent upon ey(Pignoni etal., 1997; Halder et al., 1998; Niimi et al., 1999; Michaut et al., 2003). Moreover so acts in conjunction with eya to induce eyexpression in ectopic eyes (Pignoni et al., 1997; Bonini et al., 1997).

In vertebrates, the relationship of Six3or Six6to Pax6depends upon both the species in question and the particular compartment

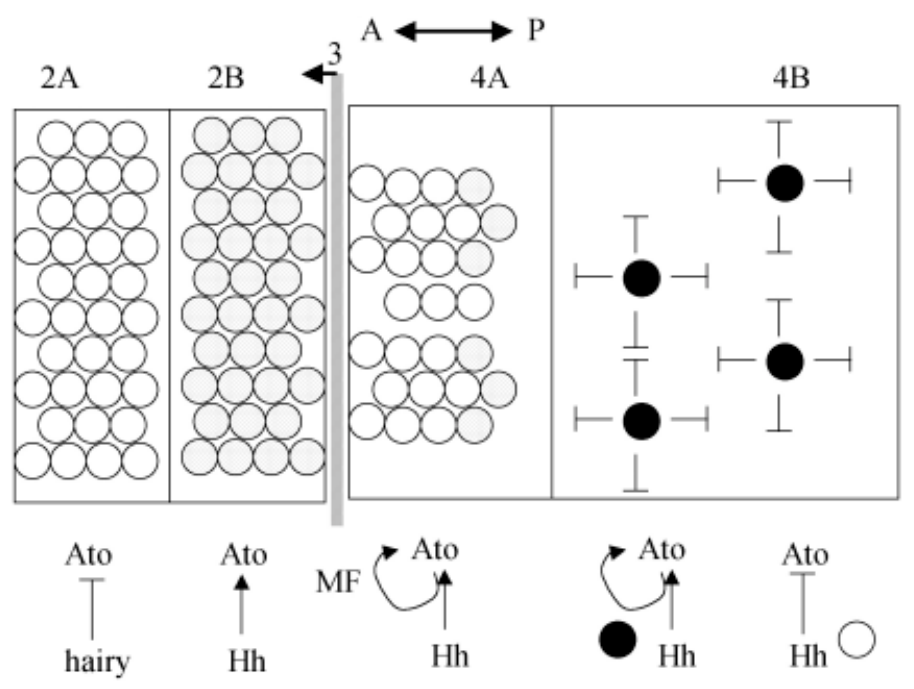

Fig. 3. Specification of the $\mathbf{R} 8$ founder cell in the Drosophila retina. Shown is a schematic representation of $R 8$ cell specification in the Drosophila eye disc. The same compartmental nomenclature is used, although compartments 2 and 4 are expanded into $A$ and $B$ sub compartments to provide more detail. Anterior $(A)$ is to the left and posterior $(P)$ is to the right. The morphogenetic furrow (MF; striped line at 3 ) progresses anteriorly. Most cells anterior to the MF, in compartment $2 \mathrm{~A}$ (open circles), do not express ato because it is repressed by hairy. In cells just anterior to the furrow, compartment 2B, Hh induces ato expression. Ato positive cells (dotted circles) are progressively restricted in number, in compartment $4 B$, until there is one founder cell (filled circles) around which each ommatidia is assembled. The restriction process occurs in four major stages: 1) induction of ato (2B); 2) restriction of ato to an intermediate group of 10-20 cells (not shown); 3 ) restriction of ato to an equivalence group of 2-3 cells (4A); and 4) restriction of ato to a single founder cell, $R 8(4 B)$. During $R 8$ differentiation, $\mathrm{hh}$ is expressed in cells that do not express ato, and it activates ato in the R8 founder cell and contributes to ato repression in other cells. 
of developing eye (Table II). In mice, Six6is expressed in the optic stalk and in the OV remnant in homozygous Pax $^{\text {Sey }}$ mice at E9.5 (Jean et al., 1999), demonstrating that Six6expression is independent of Pax6. Furthermore, Six 6 null mice have normal Pax6 expression in both the lens and retina (Li et al., 2002). Since the expression of SixG and PaxG are independent in mice, their relationship is reminiscent of that between eyand optix. Six 3 and Pax6, however, regulate each other's expression in mouse surface ectoderm derivatives (Goudreau et al., 2002). In Pax $\sigma^{\perp a c Z}$ mice, expression of Six 3 is unchanged in the retina, but is reduced in the AEL of the lens (Goudreau et al., 2002). Ectopic expression of either Pax6or Six3in lens fiber cells induces the expression of the other gene (Goudreau et al., 2002). Thus, while Six3expression is independent of Pax 6 in the retina, the relationship between Six 3 and Pax 6 in the mouse lens is interdependent, and therefore, resembles the ey-so relationship.

In Xenopus, ectopic Pax6expression expands Six3expression in the OV at the midline (presumptive optic stalk) and reduces Six 3 expression distally (presumptive NR; Chow et al., 1999). In addition, ectopic expression of either Six 3 or Six 6 induces ectopic retinas coincident with the expansion of Pax6 expression (Bernier et al., 2000). Likewise, in medaka fish, ectopic expression of either Six3or Six6expands Pax6expression and induces ectopic retinas (Loosli et al., 1999). In each of the aforementioned examples misexpression is achieved by injection of high concentrations of RNA into blastomeres during early stages of development. Thus, expression of the injected gene is not necessarily at a physiological concentration and neither the time nor the place of expression is regulated. Therefore, such overexpression experiments define relationships that may occur in normal development but do not prove that they do occur. The relationship between Pax 6 and Six 3 predicted by overexpression experiments is, however, supported by complementary reduced expression data. Down-regulation of Six 3expression by morpholino interferes with Pax6 expression, whereas interference with Pax6 expression does not interfere with Six3 (Carl et al., 2002). Thus, in both Xenopusand medaka fish Pax6and Six3/Six6are at least partly inter-dependent and, therefore, resemble ey and so.

\section{Synergism with eya}

Lastly, in Drosophila, so acts synergistically with eya, both by direct protein-protein interaction and in the cooperative induction of ectopic eyes (Pignoni et al., 1997). Optix, however, does not form a protein-protein complex with Eya (Ohto et al., 1999), and coexpression with eya does not effect the frequency of ectopic eye induction by optix (Seimiya and Gehring, 2000). Six3 also does not interact strongly with Eya proteins in biochemical assays in vitro (Ohto et al., 1999; Purcell, 2002). Six6, however, acts as a corepressor with Dach proteins both in vitro and in chromatin immunoprecipitations, suggesting that this protein-protein interaction occurs in vivo (Li et al., 2002). No direct interaction between either So or Optix and Dac proteins have been reported in the fly. This SixDach interaction may, therefore, represent a feature unique to vertebrates. However, due to their inability to interact strongly with Eya proteins, Six3 and 6 may be more similar to Optix than to So.

Thus, based on the aforementioned criteria (summarized in Table II), Six3 and Six6 in the eye do not behave exactly like so. They have some functional characteristics of both optix and so. Overall, however, they have more in common with optix than they have with so.

\section{Eyes absent related genes are not critical for vertebrate eye formation}

As stated above, Eya1 and Six3 do not interact strongly at the protein level (Ohto et al., 1999; Purcell, 2002). What then becomes of the eyacomponent of the eyparadigm in vertebrates? Are other aspects of eyafunction conserved?

Disruption of eyaactivity in the fly prevents eye formation (Bonini et al., 1997), and the collective expression of Eya1, Eya2, and Eya3 encompass most tissues of the developing mouse eye. Eya1 is expressed in the lens, OS, and NR (Xu et al., 1997). Eya2 is absent from the lens, but is expressed in the NR in a pattern complementary to Eya1 (Xu et al., 1997). In the retina, Eya1 is in the ONL and the peripheral retina, while Eya2is in the posterior region and the INL (Xu et al., 1997). Eya3 is present in the OV and the periocular mesenchyme, but is absent from the lens (Xu et al., 1997).

These expression patterns suggest that Eyagenes may play a role in vertebrate eye morphogenesis and that each Eyagene may have taken on a different component of Drosophila eya activity. Homozygous mutation of Eya1, however, results only in a mild, extrinsic eye phenotype, open eyelids at birth (Xu et al., 1999), and mice with compound homozygous mutations in both Eya1 and Eya2 also retain morphologically normal eyes (P.Y. Xu and R.L. Maas, unpublished; Purcell, 2002). The null mutation of Eya3 in mouse has not yet been reported. Thus, in the mouse, Eya1 and Eya2 are not required for eye morphogenesis and, therefore, cannot play a role comparable to the requisite role of eya in Drosophila. Three human cases, however, have been identified in which heterozygous mutation of EYA1 correlates with anterior segment defects (Azuma et al., 2000). Additional insight into the mechanism for this human defect is needed, however, since many other mutations in EYA1 have been reported that have no effect on eye development (Vervoot et al., 2002). Hopefully these mutations will ultimately provide insight into the function of Eyagenes in the vertebrate eye.

Drosophila eyais downstream of eyand critical for its function (Pignoni et al., 1997; Bonini et al., 1997). Indeed, both the frequency and size of ectopic eye induction are enhanced when eyaand eyare co-expressed (Bonini et al., 1997). In mice, neither Eya1 nor Eya2 expression is changed in the early eyes of PaxG ${ }^{\mathrm{Lac} Z}$ heterozygous mice (Goudreau et al., 2002). Unfortunately, expression of vertebrate Eya genes begins too late to reliably assess expression patterns in homozygous $\mathrm{Pax}^{\mathrm{Sey}}$ mice since the tissues in which these genes are expressed fail to form (Purcell, 2002). Clearly, however, if Eya1 and Eya2genes can be disrupted with no effect on eye morphogenesis (Xu et al., 1999; Purcell, 2002), they cannot be essential downstream mediators of Pax6 function.

At this time, there is very little evidence to support a homologous relationship between vertebrate Eya genes and fly eya. Perhaps the best evidence that these genes retain some functional homology comes from the demonstration that the mouse Eya1, Eya2, and Eya3genes can each rescue fly eye formation in eyamutants (Bonini etal., 1997; Bui etal., 2000). We know, however, that Eya1 and Eya2 have some capacity to behave like Drosophila eya with regards to the ey paradigm during organogenesis in other vertebrate tissues (Heanue et al., 1999; Xu et al., 1999; Xu et al., 2003). Nonetheless, the ability to replace eya in the Drosophila eye does not indicate that vertebrate Eya1 and Eya2have a specific role in vertebrate eye development. 


\section{Dach1 is not essential for vertebrate eye formation}

In the fly, the pattern of dacexpression coincides with that of eya (Chen etal., 1997). In the vertebrate eye, Dach 1 is expressed in the lens and the periphery of the retina (Caubit et al., 1999; Purcell, 2002), similar to the expression of Eya1 (Xu et al., 1997). Thus vertebrate Dach1 is similar to dac in its ocular co-localization with Eya1. Dach1 expression also overlaps with that of Pax6, but is significantly delayed in its time of appearance (Hammond et al., 1998; Caubit et al., 1999; Davis et al., 1999; Heanue et al., 2002). However, while loss of dac expression disrupts Drosophila eye formation (Shen and Mardon, 1997; Chen et al., 1997), homozygous mutation of Dach1 in mice has no affect on eye morphogenesis (Davis et al., 2001). Thus, while dac is essential in the fly, Dach 1 is not essential for vertebrate eye morphogenesis.

In Drosophila, dacacts downstream of ey, eyaand so(Shen and Mardon, 1997; Chen et al., 1997; Michaut et al., 2003). In mouse, expression of Dach1 in the OC is not dependent upon Pax6as its expression is maintained in the presumptive NR of homozygous Paxb ${ }^{\text {Sey }}$ mice (Heanue et al., 2002). Expression of Dach1 is, however, disrupted in the lens ectoderm of homozygous PaxGSey mice (Purcell, 2002). This loss of Dach1expression is not the result of global loss of gene expression in a quiescent tissue because other genes are still expressed (Purcell, 2002). In the fly, dac expression is involved in the maintenance of ey, eya, and so expression (Chen etal., 1997). In Dach1mutant mice, neither Pax6 nor Six 3 expression is altered in the developing eyes (Purcell, 2002). Thus, although Dach 1 is downstream of Pax 6 in the lens ectoderm, most aspects of the ey-dac relationship are missing in the vertebrate eye.

As observed for the rescue of Drosophila eyamutants with Eya1, 2 and 3, Dach2 expression in dac mutant flies rescues the eye phenotype (Heanue et al., 1999). This is not surprising since Dach2 and its relationship to Pax3, Six 1, and Eya2during somitogenesis is comparable to the relationship in the fly eyparadigm (Heanue et al., 1999). Thus, the ability of vertebrate Dach2to rescue the Drosophila dac eye phenotype reflects the conservation of the eyparadigm in vertebrate organogenesis rather than a specific conservation of Dachfunction in the vertebrate eye.

The potential conservation of the ey paradigm in vertebrate oculogenesis has received tremendous attention. In the preceding sections, we have compared each genetic component of the ey paradigm to equivalent vertebrate genetics. While homologues of all of the genes from the fly ey paradigm are expressed during development of the vertebrate eye, the function of each of these genes has not been strictly preserved. The most notable example of non-conservation is the failure of mutations in Eya1 and Eya2to produce an embryonic eye phenotype. It is intriguing to note, however, that the vertebrate genes are capable of many of the interactions present in the Drosophila eye, as evident from the vertebrate genes either rescuing Drosophila mutants or inducing ectopic eyes in the fly. This suggests that the orthologous vertebrate genes have maintained their molecular function but that the components have, to some extent, become uncoupled. In addition it is important to note that some aspects of the eyparadigm are well conserved. In particular, Pax 6 is highly reminiscent of ey, while Six 3 and Six6 have some characteristics of so. Thus, despite the lack of strict conservation of the ey paradigm, it is significant that several critical eye regulator genes have been preserved between the morphologically divergent fly and vertebrate eye.

\section{Parallel genetic hierarchies control retinal differentia- tion in the fly and vertebrates}

Interestingly, another parallel genetic pathway between Drosophila and vertebrates has also emerged between $\mathrm{R} 8$ photoreceptor differentiation and vertebrate RGC specification. Once again this conservation is found in analogous structures that are morphologically quite different. Below, we briefly highlight the genetic similarities between the retinal developmental pathways in Drosophila and vertebrates. In both systems, the transition from a naive, progenitor state to a proneural state is controlled in part by hedgehog signaling, and by the antagonistic relationship between a proneural transcriptional activator and a proneural repressor of the basic helix-loop-helix (bHLH) class.

In the Drosophila eye disc, the MF spatially and temporally precedes a wave of differentiation (Figs. 1,3). Initiation and progression of the MF depend in part upon signaling by $\mathrm{Hh}$, which is secreted from differentiating photoreceptors posterior to the MF (Dominguez and Hafen, 1997; reviewed in Treisman and Heberlein, 1998). Hh initiates photoreceptor differentiation through two distinct signals, one long-range and one short-range (Greenwood and Struhl, 1999; Kango-Singh et al., 2003). Decapentaplegic, Dpp, mediates the long-range signal within the MF (Greenwood and Struhl, 1999; Fig. 3) and facilitates the shift from a naive cell to a pre-proneural (PPN) cell. The shift to a PPN state is marked by the upregulation of the bHLH transcription factor hairy (Greenwood and Struhl, 1999; Fig. 3). Hairyis a proneural repressor and marks the PPN state (Greenwood and Struhl, 1999). In the PPN compartment, cells exit the cell cycle and prepare for neuronal differentiation (Greenwood and Struhl, 1999).

The mediator of the second, short-range signal downstream of Hh is unknown but uses the Raf pathway (Greenwood and Struhl, 1999). The result of this short-range signal is the expression of Atonal, a bHLH transcription factor that induces a proneural state (Jarman et al., 1994). Hairyand atona/share a sharp expression boundary at the border between the PPN and the proneural (PN) compartments (Fig. 3; Greenwood and Struhl, 1999). Cells that do not pass through the PPN ( hairy+) to PN (atona/+) transition do not differentiate into R8 photoreceptors (Greenwood and Struhl, 1999). Once beyond the MF, the expression of atona/becomes gradually restricted from all of the cells in the MF to one per cluster, the R8 founder cell (reviewed in Treisman and Heberlein, 1998; Frankfort and Mardon, 2002). This restriction is partially dependent on $\mathrm{Hh}$ signaling (Dominguez and Hafen, 1997; Greenwood and Struhl, 1999).

\section{A wave of Shh signaling also marks retinal differentiation in vertebrates}

In zebrafish, Shh is expressed in the retinal GCL, ventral and nasal to the optic disc (Neumann and Nuesslein-Volhard, 2000). This zone of Shhgradually spreads across the retina as a wave that temporally matches the specification of RGCs (Neumann and Nuesslein-Volhard, 2000). Disruption of Shh expression as it expands across the retina blocks both the wave of RGC differentiation, as well as the continued expression of Shh (Neumann and Nuesslein-Volhard, 2000). Similar to the secretion of Hh by differentiating photoreceptors posterior to the MF in the fly, Shh is normally secreted by RGCs in vivo, and this drives the wave of differentiation across the retina (Neumann and Nuesslein-Volhard, 
2000). During the wave of RGC specification, the number of differentiating RGCs can be increased or decreased by altering Shh levels (Zhang and Yang, 2001). Low concentrations of Shh induce an increase in the number of differentiating RGCs, while high concentrations of Shh inhibit RGC differentiation and reduce their numbers (Zhang and Yang, 2001). This is reminiscent of photoreceptor differentiation in Drosophila where Hh induces the expression of the $\mathrm{R} 8$ neuronal precursor marker, atonal, in all cells at the MF, but interferes with expression of atona/in cells deselected as the R8 neuronal precursor, posterior to the MF (Fig. 3). Alteration of the concentration of $\mathrm{Hh}$ in Drosophila alters the number of R8 neuronal precursors (Dominguez and Hafen, 1997). Thus, a wave of expression of both $\mathrm{Hh}$ and Shh drive differentiation, and their concentrations are critical for specification of appropriate numbers of either R8 founders or RGCs, respectively.

In mice, complete abolition of Shhexpression produces a single retinal anlage that fails to divide into symmetric retinal primordia, and therefore results in the formation of a single, centrally located OC (Chiang, et al., 1996). Due to the timing and severity of the phenotype resulting from mutation of Shh in mice, assessing the role of Shh in retinal specification is complicated. However, the single OC in Shh mutant mice is severely dysmorphic: the twolayered structure is inappropriately patterned along the proximaldistal axis (Chiang et al., 1996). Specifically, NR is lost at the expense of RPE, suggesting that Shh may play an important role in NR specification. Additionally, Shh expression has been observed in the NR of mice at the time of RGC specification (Jensen and Wallace, 1997). Definitive evidence of a role for Shhin mouse retinal specification awaits the generation of a conditional knock out.

\section{A family of bHLH genes specifies neuronal identity}

The mouse RGC marker, Math5, is the orthologue of the fly R8 progenitor cell marker, atonal(Brown et al., 1998). Expression of Math5precedes that of other bHLH PN genes (Ngn2, NeuroD, and Mash 1) in mice (Brown et al., 1998). Math5 is expressed initially in the mouse retina at $\mathrm{E} 11.5$ in the central $\mathrm{OC}$, and correlates with the appearance of early neurons (Brown et al., 2001; Wang et al., 2001). Math5expression expands throughout the retina in a wave and peaks at E13.5 (Brown et al., 2001; Wang et al., 2001). During RGC birth at E15.5, Math5 is expressed in the periphery of the retina where neuronal specification occurs (Brown et al., 2001; Wang et al., 2001). Similarly, the zebrafish and Xenopus atonal orthologues, ath5 and Xath5 respectively, predict the pattern of neuronal differentiation with their expression (Kaneker et al., 1997; Masai et al., 2000). Thus, the dynamic expression patterns of the vertebrate proneural genes Math5/ath5/Xath5 resemble the expression of atona/that moves across the fly eye disc in front of the MF as photoreceptor differentiation proceeds.

Mice bearing a homozygous deletion of Math5 lose up to $80 \%$ of cells expressing RGC markers. This leaves an excess of progenitor cells in the proliferative layer of the retina (Brown et al., 2001; Wang et al., 2001). The presence of these excess retinal precursor cells after the first wave of neurogenesis leads to the specification of large numbers of amacrine cells (Brown et al., 2001; Wang et al., 2001). In zebrafish, mutation of ath5 (/ak) abolishes the first wave of differentiation in the retina, which produces RGCs (Kay etal., 2001). Likewise, cells in the Drosophila eye disc that do not transition through and ato+ state, cannot differentiate into photoreceptors (Greenwood and Struhl, 1999).
In the developing vertebrate retina, the neuronal repressor Hes 1, a homologue of the fly repressor hairy, is expressed in the ventricular zone and is absent from the GCL (Tomita et al., 1996). Hes 1 positive cells remain in the proliferative layer and do not differentiate into neurons (Tomita et al., 1996). In Hes1 deficient mice, the waves of differentiation that produce the different neurons of the retina are greatly accelerated (Tomita et al., 1996), and neurogenesis proceeds at the expense of proliferation in RPCs. Loss of both proneural repressor proteins (Hairy and Extramacrochaete) in Drosophila also results in premature differentiation of photoreceptors (Brown et al., 1995). In Hes 1-/-mice, fewer progenitor cells are available for specification at each stage so the resulting retinas have very few neurons (Tomita et al., 1996). Based on these data, Hes 1 is believed to repress neurogenesis in proliferative cells, thereby preventing premature differentiation. Consistent with this idea, overexpression of Hes 1 in postnatal rat retinal progenitors increases the number of Müller glia at the expense of neurons (Furukawa et al., 2000).

Hes 1 and Math1 have an antagonistic relationship in vertebrate retinal neurogenesis. Hes 1 is expressed in progenitor cells and represses premature differentiation, while Math5 is expressed in early neural precursors and promotes RGC differentiation. Additionally, in heterozygous Pax $\sigma^{\text {Sey }}$ mice, fewer Math5 expressing cells are present, while the domain of Hes1 expression is expanded (Brown et al., 1998). In homozygous Pax6 ${ }^{\mathrm{Sey}}$ mice, Math5 expression is abolished (Brown et al., 1998). Since the loss of Math5 expression correlates with an expansion of Hes1, these data provide additional evidence for the antagonistic relationship between these genes in vertebrates. This antagonistic relationship is highly reminiscent of that observed between hairyand atona/in the fly.

\section{Summary}

In conclusion, we have reviewed the eyparadigm as characterized in Drosophila, and we have evaluated its potential conservation in vertebrates. The evidence to date does not support the idea that the entire eygenetic hierarchy is conserved in the vertebrate eye. On the other hand, some genetic parallels do exist, as Pax6 activity is highly reminiscent of $e y$, and Six 3 and Six 6 have some characteristics of $s o$. Nonetheless, it is the overall epistatic relationship amongst the vertebrate homologues of ey, so, eya, and dac that appears to be specifically absent in the vertebrate eye.

We have also briefly reviewed some aspects of neuronal specification in the vertebrate retina, as the control of both cell proliferation and RGC identity by bHLH transcription factors is highly reminiscent of $\mathrm{R} 8$ photoreceptor differentiation in the fly. Thus in both cases, specific features of developmental regulatory cassettes have been retained and re-deployed in vertebrate ocular organogenesis.

As vertebrate geneticists, how then do we best utilize the wealth of genetic information that is available to us? The aim is to continue to utilize the wealth of knowledge emerging from studies in Drosophilato guide our inquiries into mechanisms of vertebrate development. In the event that a genetic cassette is not maintained, this too is instructive, as it indicates that the particular role that the genetic hierarchy evolved to accomplish is either not relevant, or not sufficient, to meet the complexity of the vertebrate system. It is, however, increasingly clear that genetic pathways orchestrating Drosophila eye formation have been adapted in vertebrates for 
multiple organogenic processes, and that they have been partially maintained in the eye, despite the significant divergence of vertebrate and invertebrate eyes.

\section{Acknowledgements}

The authors would like to acknowledge Fang Ko for preparation of DAPI stained sections and Robert Moy for critical reading of the manuscript.

\section{References}

ASHERY-PADAN, R., and GRUSS, P. (2001). Pax6lights the way for eye development. Curr. Opin. Cell Biol. 13:706-714.

AZUMA, M., HIRAKIYAMA, A., INOUE, T., ASAKA, A., and YAMADA, M. (2000). Mutations of a human homologue of the Drosophila eyes absentgene ( $E Y A 1)$ detected in patients with congenital cataracts and ocular anterior segment anomalies. Hum. Mol. Genet. 9:3636-366.

BAKER, N.C. (2001). Cell proliferation, survival, and death in the Drosophila eye. Semin. Cell Dev. Biol. 12:499-507.

BERNIER, G., PANITZ, F., ZHOU, X., HOLLEMANN, T., GRUSS, P., and PIELER, T. (2000). Expanded retina territory by midbrain transformation upon overexpression of Six6 (Optx2) in Xenopus embryos. Mech. Dev. 93:59-69.

BONINI, N.M., BUI, W.T., GRAY-BOARD, G.L., and WARRICK, J.M. (1997) The Drosophila eyes absent gene directs ectopic eye formation in a pathway conserved between flies and vertebrates. Development 124:4819-4826.

BORSANI, G., DEGRANDI, A., BALLABIO, A., BULLFONE, A., BERNARD, L., BANFI, S., GATTUSO, C., MARIANI, M., DIXON, M., DONNAI, D., METCALFE, K., WINTER, R., ROBERTSON, M., AXTON, R., BROWN, A., VAN HEYNINGEN, V., and HANSEN, I. (1999). EYA4, a novel vertebrate gene related to Drosophila eyes absent. Hum. Mol. Genet. 8:11-23.

BROWN, N.L., SATTLER, C., PADDOCK, S.W., and CARROLL, S.B. (1995). Hairy and Emc negatively regulate morphogenetic furrow progression in the Drosophila eye. Ce//80:879-887.

BROWN, N.L., KANEKAR, S., VETTER, M.L., TUCKER, P.K., GEMZA, D.L., and GLASER, T. (1998). Math5encodes a murine basic helix-loop-helix transcription factor expressed during early stages of retinal neurogenesis. Development 125:4821-4833.

BROWN, N.L., PATEL, S., BRZEZINSKI, and GLASER, T. (2001). Math5 is required for retinal ganglion cell and optic nerve formation. Development 128:2497-2508.

BUI, Q.T., ZIMMERMAN, J.E., LIU, H., and BONINI, N. M. (2000). Molecular analysis of Drosophila eyes absentmutants reveals features of the conserved Eya domain. Genetics 155:709-720.

CARL, M., LOOSLI, F., and WITTBRODT, J. (2002) Six3 inactivation reveals its essential role for the formation and patterning of the vertebrate eye. Development 129:4057-4063.

CAUBIT, X. THANGARAJAH, R., THEIL, T., WIRTH, J., NOTHWANG, H-G., RÜTHER, U., and KRAUSS, S. (1999). Mouse Dac, a novel nuclear factor with homology to Drosophila dachshund shows a dynamic expression in the neural crest, the eye, the neocortex, and the limb bud. Dev. Dyn. 214:66-80.

CEPKO, C.L., AUSTIN, C.P., YANG, X., ALEXIADES, M., and EZZEDDINE, D. (1996). Cell fate determination in the vertebrate retina. Proc. Natl. Acad. Sci. USA 93:589-595.

CHEN, R., AMOUI, M., ZHANG, Z., and MARDON, G. (1997). Dachshundand eyes absentproteins form a complex and function synergistically to induce ectopic eye development in Drosophila. Cel/91:898-903.

CHEYETTE, B. N. R., GREEN, P. J., MARTIN, K., GARREN, H., HARTENSTEIN, V. and ZIPURSKY, S. L (1994). The Drosophila sine oculis locus encodes a homeodomain-containing protein required for the development of the entire visual system. Neuron 12: 977-996

CHIANG, C., LITINGTUNG, Y., LEE, E., YOUNG, K.E., CORDEN, J.L., WESTPHAL, H., and BEACHY, P.A. (1996) Cyclopia and defective axial patterning in mice lacking Sonic Hedgehog gene function. Nature 383:407-413.

CHOW, R.L., ALTMANN, C.R., LANG, R.A., and HAMMATI-BRIVANLOU, A. (1999). Pax6 induces ectopic eyes in a vertebrate. Development 126:4213-4222.

CZERNY, T., HALDER, G., KLOTER, U., SOUABNI, GEHRING, W.J., and BUSSLINGER, M. (1999). Twin of ey, a second Pax6 gene of Drosophila, acts upstream of eyeless in the control of eye development. Mol. Cel/3:297-307.

DAVIS, R.J., SHEN, W., HEANUE, T.A. and MARDON, G. (1999). Mouse Dach, a homologue of Drosophila dachshund, is expressed in the developing retina, brain, and limbs. Dev. Genes Evol. 209:526-536.

DAVIS, R.J., SHEN, W., SANDLER, Y.I., AMOUI, M., PURCELL, P., MAAS, R., OU, C.N., VOGEL, H., BEAUDET, A.L., and MARDON, G. (2001) Dach1mutant mice bear no gross abnormalities in eye, limb, and brain development and exhibit postnatal lethality. Mol. Cell Biol. 21:1484-90.

DESPLAN, C. (1997). Eye development: governed by a dictator or a junta? Ce//91:861864.

DOMINGUEZ, M. and HAFEN, E. (1997) Hedgehog directly controls initiation and propagation of retinal differentiation in the Drosophila eye. Genes Dev. 11:32543264.

DOMINGUEZ, M., FERRES-MARCO, D., GUTIERREZ-AVINO, F.J., SPEICHER S.A., and BENEYTO, M. (2004). Growth and specification of the eye are controlled independently by Eyegone and Eyeless in Drosophila melanogaster. Nat. Genet. 36: 31-39.

FRANKFORT, B.J. and MARDON, G. (2002) R8 development in the Drosophila eye a paradigm for neural selection and differentiation. Development 129:1295-1306.

FURUKAWA, T., MUKHERJEE, S., BAO, Z.Z., MORROW, E.M., and CEPKO, C.L. (2000). Rax, Hes1, and Notch1 promote the formation of Müller glia by postnatal progenitor cells. Neuron 26:383-394.

GALLARDO, M.E., LOPEZ-RIOS, J., FERNAUD-ESPINOSA, I., GRANADINO, B., SANZ, R., RAMOS, C., AYUSO, C., SELLER, M.J., BRUNNER, H.G., BOVOLENTA P., and RODRIGUEZ DE CÓRDOBA, S. (1999). Genomic cloning and characterization of the human homeobox gene $S / X G$ reveals a cluster of $S / X$ genes in chromosome 14 and associates $S / X 6$ hemizygosity with bilateral anophthalmia and pituitary anomalies. Genomics 61:82-91.

GEHRING, W.J. and IKEO, K. (1999). Pax6 mastering eye morphogenesis and eye evolution. Trends Genet. 15: 371-377.

GHANBARI, H., SEO, H-C., FJOSE, A. and BRÄNDLI, A.W. (2001). Molecular cloning and embryonic expression of Xenopus Sixhomeobox genes. Mech. Dev. 101:271277

GOUdREAU, G., PETROU, P., RENEKER, L.W., GRAW, J., LOSTER, J., and GRUSS, P. (2002) Mutually regulated expression of Pax6 and Six 3 and its implications for the Pax6 haploinsufficient lens phenotype. Proc. Natl. Acad. Sci. USA 99:8719-8724.

GLASER, T., JEPEAL, L., EDWARDS, J.G., YOUNG, S.R., FAVOR, J. and MAAS, R.L. (1994). PAX6 gene dosage effect in a family with congenital cataracts, aniridia, anophthalmia and central nervous system defects. Nat. Genet. 7:463-471.

GREENWOOD, S. and STRUHL, G. (1999). Progress of the morphogenetic furrow in the Drosophila eye: the roles of Hedgehog, Decapentaplegic, and the Raf pathway. Development 126:5795-5808.

HALDER, G., CALLAERTS, P., and GEHRING, W.J. (1995). Induction of ectopic eyes by targeted expression of the eyeless gene in Drosophila. Science 267:1788-92.

HALDER, G., CALLAERTS, P., FLISTER, S., WALLDORF, U., KLOTER, U., and GEHRING, W.J. (1998). Eyeless initiates the expression of both sine oculis and eyes absentduring Drosophilacompound eye development. Development125:21812191.

HAMMOND, K. L., HANSON, I. M., BROWN, A. G., LETTICE, L.A., and HILL, R.E. (1998). Mammalian and Drosophila dachshundgenes are related to the Skiprotooncogene and are expressed in eye and limb. Mech. Dev. 74:121-131.

HANSON, I.M. (2001). Mammalian homologues of the Drosophila eye specification genes. Semin. Cell Dev. Biol. 12:475-484.

HAUCK, B., GEHRING, W. J., and WALLDORF, U. (1999). Functional analysis of an eye specific enhancer of the eyelessgene in Drosophila. Proc. Natl. Acad. Sci. USA 96:564-569.

HEANUE, T.A., RESHEF, R. DAVIS, R.J., MARDON, G., OLIVER, G., TOMAREV, S., LASSAR, A.B., and TABIN, C.J. (1999) Synergistic regulation of vertebrate muscle development by Dach2, Eya2, and Six 1, homologs of genes required for Drosophila eye formation. Genes Dev. 15:3231-43.

HEANUE, T.A., DAVIS, R.J., ROWITCH, D.H., KISPERT, A., MCMAHON, A.P., MARDON, G., and TABIN, C.J. (2002). Dach1, a vertebrate homologue of Drosophila dachshund, is expressed in the developing eye and ear of both chick and mouse and is regulated independently of Pax and Eya genes. Mech. Dev. 111:75-87 
HEATH, S. K., CARNE, S., HOYLE, C., JOHNSON, K. J., and WELLS, D.J. (1997). Characterization of expression of $m D M A H P$, a homeodomain encoding gene at the DM locus. Hum. Mol. Genet. 6:651-657.

HILL, R.E., FAVOR, J. HOGAN, B.L., TON, C.C., SAUNDERS, G.F., HANSON, I.M., PROSSER, J., JORDAN, T. et al. (1991). Mouse Small eyeresults from mutations in a paired-like homeobox containing gene. Nature 354:522-525.

HSIUNG, F. and MOSES, K. (2002). Retinal development in Drosophila: specifying the first neuron. Hum. Mol. Genet. 11:1207-1214.

JANG, C.C., CHAO, J.L., JONES, N., YAO, L.C., BESSARAB, D.A., KUO, Y.M., JUN, S., DESPLAN, C., BECKENDORF, S.K., and SUN, Y.H. (2003). Two Paxgenes, eye gone and eyeless, act cooperatively in promoting Drosophila eye development. Development 130:2939-51.

JARMAN, A.P., GRELL, E.H., ACKERMAN, L., JAN, L.Y., and JAN, Y.N. (1994). Atona/is the proneural gene for Drosophila photoreceptors. Nature369:398-400.

JEAN, D., BEIMER, G., and GRUSS, P. (1999). Six6 (optx2) is a novel murine Six3 related homeobox gene that demarcates the presumptive pituitary/hypothalamic axis and ventral optic stalk. Mech. Dev. 84:31-40.

JENSEN, A.M. and WALLACE, V.A. (1997) Expression of Sonic hedgehog and it putative role as a precursor cell mitogen in developing mouse retina. Development 124:363-371.

KANEKER, S., PERRON, M., DORSKY, R., HARRIS, W.A., JAN, L.Y., JAN, Y.N., and VETTER M.L. (1997). Xath5 participates in a network of bHLH genes in the developing Xenopus retina. Neuron 19:981-994.

KANGO-SINGH, M., SINGH, A., and SUN, H. (2003) Eyeless collaborates with Hedgehog and Decapentaplegic signaling in Drosophilaeye induction. Dev. Biol. 256:49-60.

KAY, J.N., FINGER-BAIER, K.C., ROESER, T., STAUB, W., and BAIER, H. (2001) Retinal ganglion cell genesis requires lakritz, a zebrafish atonal homologue. Neuron 30:725-736.

KAWAKAMI, K., OHTO, H., TAKIZAWA, T., and SAITO, T. (1996). Identification and expression of six family genes in mouse retina. FEBS Lett.393:259-263.

KAWAKAMI, K., OHTO, H., IKEDA, K., and ROEDER, R.G. (1996b). Structure, function, and expression of a murine homeobox protein AREC3, a homologue of Drosophila sine oculis gene product, and implication in development. Nucleic Acids Res. 24:303-310.

KAWAKAMI, K. SATO, S., and IKEDA, K. (2000) Six family genes - structure and function as transcription factors and their roles in development. BioEssays22:616626.

KLESERT, T. R., CHO, D.H., CLARK, J. I., MAYLIE, J., ADELMAN, J., SNIDER, L., YUEN, E. C., SORIANO, P., and TAPSCOTT, S. J. (2000). Mice deficient in Six5 develop cataracts: implications for myotonic dystrophy. Nat. Genet. 25:105-109.

KOBAYASHI, M.,OSANAI, H., KAWAKAMI, K., and YAMAMOTO, M. (2000). Expression of three zebrafish Six4 genes in cranial sensory placodes and developing somites. Mech. Dev. 98:151-155.

LACLEF, C., SOUIL, E., DEMIGNON, J., and MAIRE, P. (2003). Thymus, kidney, and craniofacial abnormalities in Six1 deficient mice. Mech. Dev. 120: 669-679.

LI, X., PERISSI, V., LIU, F., ROSE, D.W., and ROSENFELD, M.G. (2002) Tissuespecific regulation of retinal and pituitary precursor cell proliferation. Science 297:1180-1183

LI, X., OGHI, K.A., ZHANG, J., KRONES, A., BUSH, K.T., GLASS, C.K., NIGAM, S.K., AGGARWAL, A.K., MAAS, R., ROSE, R.W., and ROSENFELD, M.G. (2003). Eya protein phosphatase activity regulates Six1-Dach-Eya transcriptional effects in mammalian organogenesis. Nature 426:247-254.

LOOSLI, F., WINKLER, S., and WITTBRODT, J. (1999) Six3overexpression initiates the formation of ectopic retina. Genes Dev. 13:649-654.

MACDONALD, R., BARTH, K.A., XU, Q., HOLDER, N., MIKKOLA, I., and WILSON, S.W. (1995). Midline signaling is required for Paxgene regulation and patterning of the eyes. Development 121:3267-3278.

MASAI, I., STEMPLE, D.L., OKAMOTO, H., and WILSON, S.W. (2000). Midline signals regulate retinal neurogenesis in zebrafish. Neuron 27:251-263.

MARQUARDT, T. and GRUSS, P. (2002) Generating neuronal diversity in the retina: one for nearly all. Trends Neurosci. 25:32-38.

MCCABE, K.L, GUNTER, E.C., and REH, T.A. (1999). The development of pattern of retinal ganglion cells in the chick retina: mechanisms that control differentiation. Development 126:5713-5724.
MICHAUT, L., FLISTER, S., NEEB, M., WHITE, K.P., CERTA, U., and GEHRING, W.J. (2003). Analysis of the eye developmental pathway in Drosophila using DNA microarrays. Proc. Natl. Acad. Sci. USA 100:4024-4029.

NEUMANN, C.J., and NUESSLEIN-VOLHARD, C. (2000). Patterning of the zebrafish retina by a wave of sonic hedgehog activity. Science 289:2137-2139.

NIIMI, T. SEIMIYA, M., KLOTER, U., FLISTER, S., and GEHRING, W.J. (1999). Direct regulatory interaction of the eyeless protein with an eye-specific enhancer in the sine oculis gene during eye induction in Drosophila. Development 126:2253-2260.

OGINO, H., and YASUDA, K. (2000). Sequential activation of transcription factors in lens induction. Dev. Growth Diff. 42:437-448.

OHTO, H., KAMADA, S., TAGO, K., TOMINAGA, S.I., OZAKI, H., SATO, S., and KAWAKAMI, K. (1999). Cooperation of Six and Eya in activation of their target genes through nuclear translocation of Eya. Mol. Cell Biol. 19:6815-6824.

OLIVER, G., MAILHOS, A., WEHR, R., COPELAND, N.G., JENKINS, N.A., and GRUSS, P. (1995). Six3, a murine homologue of the sine oculisgene, demarcates the most anterior border of the developing neural plate and is expressed during eye development. Development 121: 4045-4055.

OLIVER, G., WEHR, R., JENKINS, N.A., COPELAND, N. G. CHEYETTE, B. N. R. HARTENSTEIN, V., ZIPURSKY, L., and GRUSS P. (1995b). Homeobox genes and connective tissue patterning. Development 121:693-705.

OZAKI, H., WANTABE, Y., TAKAHASHI, K., KITAMURA, K., TANAKA, A., URASE, K., MOMOI, T., SUDO, K., SAKAGAMI, J., ASANO, M., IWAKURA, Y., and KAWAKAMI, K. (2001). Six4 a putative myogeningene regulator, is not essential for mouse embryonal development. Mol. Cell Biol. 21:3343-3350.

PASQUIER, L., DUBOURG, C., BLAYAU, M., LAZARO, L., LE MAREC, B., DAVID, V., and ODENT, S. (2000). A new mutation in the six-domain of $S / X 3$ gene causes holoprosencephaly. Eur. J. Hum. Genet. 8:797-800

PIGNONI, F., HU, B., ZAVITZ, K.H., XIAO, J., GARRITY, P.A., and ZIPURSKY, S.L. (1997). The eye specification proteins So and Eya form a complex and regulate multiple steps in Drosophila eye development. Cel/91:881-891.

PLAZA, S. DOZIER, C., and SAULE, S. (1993). Quail Pax-6 (Pax-QNR) encodes a transcription factor able to bind and trans-activate its own promoter. Cel/ Growth Differ. 4:1041-1050.

PURCELL, P. (2002) Genes involved in early development of the mouse sensory placodes. Thesis, Harvard University.

QUIRING, R., WALLDORF, U., KLOTER, U., and GEHRING, W.J. (1994). Homology of the eyeless gene of Drosophila to the small eye gene in mice and Aniridia in humans. Science $265: 783$

SARKAR, P. S., APPUKUTTAN, B., HAN, J., ITO, S., AI, C., TSAI, W., CHAI, Y., STOUT, J. T., and REDDY, S. (2000). Heterozygous loss of Six 5 in mice is sufficient to cause ocular cataracts. Nat. Genet. 25:110-114.

SEIMIYA, M. and GEHRING, W.J. (2000). The Drosophila homeobox gene optix is capable of inducing ectopic eyes by an eyeless-independent mechanism. Development 127:1879-1886.

SERIKAKU, M. A. and O'TOUSA, J. E (1994) Sine oculisis a homeobox gene required for Drosophila visual system development. Genetics 138: 1137-1150.

SHEN, W. and MARDON, G. (1997). Ectopic eye development in Drosophilainduced by directed dachshundexpression. Development 124:45-52.

SIMPSON, T. A. and PRICE, D. J. (2002). Pax6, a pleiotropic player in development. BioEssays 24:1041-1051.

TOMITA, K, ISHIBASHI, M. NAKARHARA, K., ANG, S.L., NAKANISHI, S. GUILLEMOT, F., and KAGEYAMA, R. (1996) Mammalian hairyand Enhancer of split homologue 1 regulates differentiation of retinal neurons and is essential for eye morphogenesis. Neuron 16:723-34.

TORRES, M., GOMEZ-PARDO, E., and GRUSS, P. (1996). Pax2contributes to inner ear patterning and optic nerve trajectory. Development 122:3381-3391.

TOY, J., YANG, J-M., LEPPERT, G.S., and SUNDIN, O.H. (1998). The optx2 homeobox gene is expressed in early precursors of the eye and activates retinaspecific genes. Proc. Natl. Acad. Sci. USA 95:10643-10648.

TOY, J. and SUNDIN, O.H. (1999). Expression of the Optx2 homeobox gene during mouse development. Mech. Dev. 83:183-186.

TREISMAN, J.E., and HEBERLEIN, U. (1998). Eye development in Drosophila. formation of the eye field and control of differentiation. Curr. Top. Dev. Biol. 39:119-158. 
VANHEYNINGAN, V. and WILLIAMSON, K. A. (2002) PAXGin sensory development. Hum. Mol. Genet. 11:1161-1167.

VERVOOT, V.S., SMITH, R.J., O'BRIEN, J., SCHROET, R., ABBOTT, A., STEVENSON, R.E., and SCHWARTZ, C.E. (2002) Genomic rearrangements of EYA1 account for a large fraction of families with BOR syndrome. Eur. J. Hum. Genet. 10:757-766.

WALTHER, C. and GRUSS, P. (1991). Pax6, a murine paired box gene, is expressed in the developing CNS. Development 113:1435-1449.

WALLIS, D. E., ROESSLER, E., HEHR, U., NANNI, L., WILTSHIRE, T., RICHIERICOSTA, A., GILLESEN-KAESBACH, G., ZACKAI, E. H., ROMMENS, J., and MUENKE, M. (1999). Mutations in the homeodomain of the human S/X3 gene cause holoprosencephaly. Nat. Genet. 22:196-198.

WINCHESTER, C. L., FERRIER, R. K., SERMONI, A., CLARK, B.J., and JOHNSON, K. J. (1999). Characterization of the expression of DMPKand SIX5in the human eye and implications for pathogenesis in myotonic dystrophy. Hum. Mol. Genet. 8:481-492.
WANG, S.W., KIM, B.S., DING, K., WANG, H., SUN, D., JOHNSON, R.L., KLEIN, W.H., and GAN, L. (2001). Requirement for Math5 in the development of retinal ganglion cells. Genes Dev. 15:24-29.

WAWERSIK, S., and MAAS, R.L. (2000). Vertebrate eye development as modeled in Drosophila. Hum. Mol. Genet. 9:917-925.

XU, P., WOO, I., HER, H., BEIER, D.R., and MAAS, R.L. (1997). Mouse Eya homologues of the Drosophila eyes absentgene require Pax6 for expression in lens and nasal placode. Development 124:219-231.

XU, P., ADAMS, J., PETERS, H., BROWN, M.C., HEANEY, S. and MAAS, R.L. (1999). Eya1 deficient mice lack ears and kidneys and show abnormal apoptosis of organ primordial. Nat. Genet. 23:113-117.

XU, P., ZHENG, W.M., HUANG, L., MAIRE, P., LACLEF, C., and SILVIUS, D. (2003). Six 1 is required for the early organogenesis of mammalian kidney. Development 130:3085-3094.

ZHANG, X-M., and YANG, X-J. (2001). Regulation of retinal ganglion cell production by Sonic hedgehog. Development 128:943-957. 